\title{
The Real-World Medicare Costs of Alzheimer Disease: Considerations for Policy and Care
}

\author{
Bruce Pyenson, FSA, MAAA; Tia Goss Sawhney, DrPH, FSA, MAAA; Charles Steffens, ASA, MAAA; \\ David Rotter, PhD; Susan Peschin, MHS; James Scott, JD; and Ellen Jenkins, BS
}

\begin{abstract}
BACKGROUND: Headlines in popular media suggest that Alzheimer disease will bankrupt the Medicare program. Indeed, Alzheimer disease affects more than 5 million older Medicare beneficiaries.

OBJECTIVE: To compare total Medicare-covered (allowed) costs of patients with Alzheimer disease with the risk adjusted costs of beneficiaries without dementia over their last years of life, using claims data.

METHODS: Using the Medicare 5 Percent Limited Data Set claim files from 2006-2015, we conducted a cost impact analysis of costs for up to 8 years before the year of death. Risk adjustment was performed at a beneficiary level using Medicare's 2015 Hierarchical Condition Categories. Beneficiaries were classified into dementia categories based on their diagnoses during the last 3 years of life. Costs were trend adjusted to 2015.

RESULTS: This study found that $40 \%$ of deceased beneficiaries have Alzheimer disease or unspecified dementia diagnoses in their claims history. In their last 9 years of life, Alzheimer disease added about $11 \%$ to the average $\$ 17,000$ per year Medicare cost for same-risk beneficiaries without dementia.
\end{abstract}

CONCLUSIONS: Like many diseases, Alzheimer disease and dementia are associated with aging, but unlike other diseases, families and Medicaid, rather than Medicare, bear most of the substantial cost burden. As research continues into Alzheimer treatments, it is not too early to consider how to better integrate Medicare and Medicaid to fund and improve patient outcomes, which will likely involve better diagnosis, treatment, and care coordination.

J Manag Care Spec Pharm. 2019;25(7):800-09

Copyright $\odot 2019$, Academy of Managed Care Pharmacy. All rights reserved.

\section{What is already known about this subject}

It is well known that the incidence of Alzheimer disease increases with age, and most patients are Medicare beneficiaries.

The cost burden of caring for patients with Alzheimer disease includes not only medical expenses but also supportive care, paid by Medicaid and families.

\section{What this study adds}

This study found that, over the 9 years before death, Medicare costs for patients with Alzheimer disease are only 11\% higher than for beneficiaries without Alzheimer disease, after adjusting for the risk of comorbidities.

Many cases of Alzheimer disease are found during an inpatient admission, but the vast majority of such admissions appear to be unrelated to Alzheimer disease or related symptoms, which suggests that an Alzheimer diagnosis is often an incidental finding. In the last year of life, patients with Alzheimer disease incurred Medicare costs that were $\$ 1,342$ less than those of nondementia beneficiaries.

A lzheimer disease is the most common form of dementia among Medicare beneficiaries. ${ }^{1}$ It is a chronic, degenerative brain disease that destroys memory and thinking skills and the ability for self-care. ${ }^{2}$ Behavior and personality changes resulting from Alzheimer disease, as well as diminished ability to perform activities of daily living, can make caring for the patient by the patient's family and other caregivers challenging and debilitating., ${ }^{3,4}$ We examined the incremental cost to Medicare of Alzheimer disease and found that Medicare spending on Alzheimer disease is lower than reported in the news and elsewhere.

Alzheimer disease causes changes to the brain years before clinical symptoms appear. Alzheimer diagnosis, should it occur, is a rule-out diagnosis based on the lack of other explanations for the patient's memory, behavior, and personality changes. ${ }^{5,6}$ Often, a patient's specific type of dementia may be confirmed only through an autopsy, but these are rarely done.,

Experts suggest that more than 5 million Americans have Alzheimer disease. ${ }^{5}$ Like many chronic diseases, Alzheimer risk increases with age. Dementia incidence doubles every 5 years from ages 65 to 90 years and continues to increase beyond age 90 years. ${ }^{9}$ More than $15 \%$ of older U.S. adults aged in their 80 s, and about $50 \%$ of those in their 90 s have dementia. ${ }^{10}$ Medicare covers nearly all U.S. residents aged 65 years and older, ${ }^{11}$ so Alzheimer disease is important to Medicare. The U.S. Census Bureau projects that the U.S. population aged 85 years and older, ages most likely to have Alzheimer disease, will increase by 8 million (126\%) by 2040.12 
An authoritative source on aging is the Health and Retirement Study (HRS) sponsored by the National Institute on Aging and the Social Service Administration. HRS used a detailed in-home cognitive assessment to identify retirees with dementia-related cognitive and functional impairments. The HRS estimated that dementia cost Medicare, Medicaid, other payers, and families $\$ 28,501$ (2015 U.S. dollars) per patient per year, not including $\$ 27,789$ for the value of family caregiving. Medicare paid $\$ 2,752$ of the $\$ 56,290$ annual cost. ${ }^{13}$ A separate study of HRS data from 2005 to 2010 concluded that Medicare expenditures were similar among members who died from dementia, heart disease, cancer, or other causes. ${ }^{14}$

However, news organizations such as PBS, Fox News, and Forbes have reported that the expected increasing numbers of beneficiaries with Alzheimer disease may bankrupt the Medicare program. These organizations have also reported that Medicare beneficiaries with Alzheimer disease have Medicare costs that are 2 or 3 times the costs of beneficiaries without Alzheimer disease. ${ }^{15-20}$ Similar concerns have been raised for decades. ${ }^{21,22}$

The relatively low Medicare spending on Alzheimer disease reported by HRS makes sense. Medicare pays for medical care and only some short-term supportive care. In 2013, Medicare declined to cover amyloid positron emission tomography (PET) imaging, which can provide early Alzheimer diagnosis, outside of a clinical trial, citing insufficient evidence that the imaging would make a difference for patients with a disease for which there is no cure and limited symptomatic treatment. ${ }^{23}$ However, in 2017, the Centers for Medicare \& Medicaid Services (CMS) implemented a new primary care code (99483) for cognition and functional assessment and for care planning for beneficiaries with cognitive impairment. Although several drugs treat some symptoms of Alzheimer disease, there are currently no disease-modifying therapies despite the billions of dollars being invested in research., ${ }^{5,24}$ In contrast, cancer, heart disease, and other diseases of aging have significant medical and prescription drug costs.

Low Medicare costs for Alzheimer disease do not mean low health system costs. Medicaid, a secondary payer for people with Medicare, is an important source of funding for Alzheimer care. Medicaid pays for supportive care not covered by Medicare when the beneficiary is sufficiently impoverished to meet Medicaid's income and asset tests. Medicaid is a program jointly funded by the federal government and states and, by statute, must provide coverage for nursing home care and some home health services. ${ }^{25}$ Medicaid pays for most of U.S. nursing home care costs, and more than $60 \%$ of nursing home residents have moderate to severe dementia. Most states have waivers that expand coverage to home and community-based services and support for Medicaid beneficiaries who are at risk of needing nursing home care. ${ }^{26}$ Medicaid also pays the Medicare Part B and Part D premiums and may pay the Medicare cost sharing for dual eligible beneficiaries.

Alzheimer disease is the focus of intense scientific research, patient advocacy efforts, and policy discussion, with high financial stakes for payers that include Medicare, Medicaid, commercial insurers, patients, and their families. The HRS found that Medicare costs for Alzheimer decedents are similar to costs for beneficiaries with other end-of-life conditions, but other reports show a very high cost burden of Alzheimer disease for Medicare. ${ }^{15-22}$ Our study directly addressed this issue by using Medicare claims data over a 9-year period, which is much larger than the HRS dataset, in order to estimate the Medicare incremental cost of Alzheimer disease. While we wait for future treatments, this information can be used to guide the debates over funding and care for patients with Alzheimer disease.

\section{Methods}

\section{Data}

We used the Medicare 5 Percent Limited Data Set claims files for 2006-2015..$^{27}$ These files contain all Medicare-paid hospital and medical (Parts A and B) claims for a balanced 5\% sample of beneficiaries. The data include diagnosis and procedure codes, site of service, and beneficiary information such as Medicaid eligibility status, date of death, and enrollment in a health maintenance organization. The data allow tracking of beneficiaries across years.

\section{Population}

Our study population consisted of 384,008 Medicare fee-forservice beneficiaries aged 69 years or older (year of death minus year of birth) who died in 2010-2015 and who had at least 3 full calendar years of Parts A and B coverage before their year of death (waterfall analysis is available from the authors by request).

Using diagnoses from the year of death and the previous 3 years, we classified each decedent on a hierarchical basis as having at least 1 International Classification of Diseases, Ninth Revision, Clinical Modification (ICD-9-CM) or International Classification of Diseases, Tenth Revision, Clinical Modification (ICD-10-CM) diagnosis code in any position on an eligible claim indicating Parkinson disease, Alzheimer disease, other specified dementia (e.g., vascular dementia), general dementia (dementia of unspecified pathology), or no dementia. Parkinson disease is at the top of the hierarchy to avoid attributing Parkinson costs to Alzheimer disease. Parkinson disease patients often have dementia symptoms similar to people with Alzheimer disease even though the 2 dementias have distinct pathologies. ${ }^{28}$ Decedents classified as having Parkinson disease or other specified dementias were excluded. 
The Real-World Medicare Costs of Alzheimer Disease: Considerations for Policy and Care

TABLE 1 Characteristics of the Study Population

\begin{tabular}{|c|c|c|c|c|c|c|c|c|c|c|}
\hline \multirow[b]{3}{*}{$\begin{array}{l}\text { Dementia } \\
\text { Classification }\end{array}$} & \multicolumn{2}{|c|}{ Study Population } & \multicolumn{8}{|c|}{ Classifications of Interest } \\
\hline & \multirow[b]{2}{*}{$\mathbf{n}$} & \multirow[b]{2}{*}{$\%$} & \multicolumn{3}{|c|}{ Age at Death (in years), $\mathbf{n}$} & \multicolumn{3}{|c|}{ Female (by age), \% } & \multicolumn{2}{|c|}{ Average } \\
\hline & & & $69-79$ & $80-89$ & $90+$ & $69-79$ & $80-89$ & 90 & Age at Death & $\begin{array}{c}\text { Years of } \\
\text { Data }\end{array}$ \\
\hline Parkinson disease & 24,134 & 7 & - & - & - & - & - & - & - & - \\
\hline Alzheimer disease & 71,969 & 21 & 11,245 & 35,855 & 24,869 & $56^{\mathrm{a}}$ & $65^{\mathrm{a}}$ & $76^{\mathrm{a}}$ & $86.4^{\mathrm{a}}$ & 5.9 \\
\hline Specific dementia & 11,969 & 4 & - & - & - & - & - & - & - & - \\
\hline General dementia & 59,886 & 18 & 11,858 & 26,587 & 21,441 & $53^{\mathrm{a}}$ & $60 \mathrm{a}$ & $72^{\mathrm{a}}$ & $86.0^{\mathrm{a}}$ & 6.3 \\
\hline No dementia & 170,330 & 50 & 71,194 & 69,302 & 29,834 & $45^{\mathrm{a}}$ & $51^{\mathrm{a}}$ & $64^{\mathrm{a}}$ & $81.7^{\mathrm{a}}$ & 5.7 \\
\hline Total & 338,288 & 100 & 94,297 & 131,744 & 76,144 & $47^{\mathrm{a}}$ & $57^{a}$ & $70^{\mathrm{a}}$ & $83.7^{a}$ & 5.9 \\
\hline
\end{tabular}

\section{Calculating Costs}

For each decedent, we summed Medicare-covered (allowed) Part A and Part B costs by year for the calendar year of death and for each calendar year up to 8 years before death. Allowed costs included both amounts paid by Medicare and cost sharing paid by beneficiaries or Medicare supplement plans. We adjusted costs to 2015 levels by applying Part A and Part B trends developed from reports of the Medicare board of trustees. ${ }^{29}$

We calculated a risk adjustment factor for each beneficiary and calendar year using the 2015 CMS-Hierarchical Condition Category (HCC) model. ${ }^{30} \mathrm{CMS}$ uses the HCCs prospectively for the Medicare Advantage program and the Medicare accountable care organization programs. The HCCs use the beneficiary's diagnosis codes, age, sex, and other characteristics from 1 calendar year to produce a score that predicts the beneficiary's spending in the next calendar year. The HCC model produces approximately 100 categories of risk factors that are summed to produce a risk score for each individual. For some diseases, such as cancer, the HCCs have distinct categories to reflect different expected costs for different cancers. The HCCs contain interaction terms, for example, capturing the interaction of certain behavioral conditions and heart failure. Dementia diagnoses are not inputs for the 2015 HCC model. However, the HCC risk scores are good cost predictors for Medicare dementia patients. ${ }^{31}$

To avoid the confounding effects of dementias on a beneficiary's Medicaid eligibility or institutionalization, we used noninstitutional, non-Medicaid risk factors. Because the average of beneficiaries' risk scores has increased over years, we adjusted 2007-2014 risk scores to 2015 levels by calculating average risk factors by year for the entire study population and developing risk-score-trend adjustment factors relative to the 2015 average.

We calculated total non-risk-adjusted and total risk-adjusted allowed costs per beneficiary per calendar year before death. We used these to calculate cost differentials for the Alzheimer disease and general dementia cohorts compared with the no-dementia decedent cohorts after normalizing costs of the dementia and no dementia cohorts for the age distribution and risk scores of the Alzheimer decedent cohort.

We also calculated the proportion of beneficiaries who were dual eligible for Medicaid by dementia cohort and by calendar year before death and costs by type of service. For the Alzheimer population, we examined inpatient admissions in the year of the first Alzheimer diagnosis and the years immediately before and after by diagnosis-related group (DRG).

$P$ values were calculated using a chi-square test for categorical variables and t-tests for continuous variables when comparing between population cohorts. We used repeated measures of analysis of variance to compare the average cost per beneficiary. Analysis was conducted with SAS software package version 9.4 (SAS Institute, Cary, NC). See Appendix A for methodology details (available in online article).

\section{Results}

Our study population included 338,288 decedent Medicare beneficiaries, of which $21 \%(71,969)$ were classified at death as having Alzheimer disease, $18 \%(59,886)$ as having general dementia, and $50 \%(170,330)$ as having no dementia. Another $11 \%(36,103)$ were classified at death as having Parkinson disease or other specific dementias. Decedents with Alzheimer disease were 4.7 years older than decedents with no dementia and 0.3 years older than decedents with general dementia $(P<0.01$ for both comparisons). Individuals in the study population had an average of 5.9 years of Medicare history in our data, including an average of 0.5 year in the calendar year of death, with a range of 3-9 years (Table 1). At all ages, decedents with Alzheimer disease or general dementia were more likely to be female than decedents with no dementia $(P<0.01)$.

We observed that beneficiaries with an incident Alzheimer diagnosis code were $147 \%$ more likely to have an inpatient hospital admission during their incident calendar year than the year before and $66 \%$ more likely than the year after the incident year. However, the DRG of these admissions indicated dementia or behavioral conditions in only $11 \%$ of the cases. 
The Real-World Medicare Costs of Alzheimer Disease: Considerations for Policy and Care

TABLE 2 Per-Beneficiary Yearly Medicare Costs Before Death by Dementia Classificationa

\begin{tabular}{|c|c|c|c|c|c|c|}
\hline \multirow{3}{*}{$\begin{array}{l}\text { Year Before } \\
\text { Death }\end{array}$} & \multicolumn{3}{|c|}{ Dementia Classification } & \multicolumn{3}{|c|}{ Dementia Classification } \\
\hline & Alzheimer Disease & General Dementia & No Dementia & Alzheimer Disease & General Dementia & No Dementia \\
\hline & \multicolumn{3}{|c|}{ Number of Beneficiaries } & \multicolumn{3}{|c|}{ Costs per Beneficiary, \$ } \\
\hline 8 & 10,562 & 11,619 & 21,931 & $10,291^{b}$ & $10,001^{b}$ & 9,100 \\
\hline 7 & 21,392 & 22,811 & 46,132 & $11,002^{b}$ & 10,884 & 9,932 \\
\hline 6 & 33,109 & 34,012 & 73,212 & $12,242^{b}$ & $11,953^{b}$ & 10,722 \\
\hline 5 & 45,790 & 44,322 & 103,389 & $13,636^{b}$ & $13,313^{b}$ & 11,706 \\
\hline 4 & 58,765 & 52,304 & 135,569 & $15,520^{b}$ & $14,763^{b}$ & 13,108 \\
\hline 3 & 71,969 & 59,886 & 170,330 & $18,034 \mathrm{~b}$ & $16,808^{b}$ & 14,467 \\
\hline 2 & 71,969 & 59,886 & 170,330 & $21,352^{\mathrm{b}}$ & $20,291^{\mathrm{b}}$ & 17,402 \\
\hline 1 & 71,969 & 59,886 & 170,330 & 29,483 & $29,300^{b}$ & 25,921 \\
\hline$\underline{0}$ & 71,969 & 59,886 & 170,330 & $31,734^{b}$ & 34,017 & 33,076 \\
\hline Total & 71,969 & 59,886 & 170,330 & 163,295 & 161,331 & 145,434 \\
\hline Years, $\mathrm{n}^{\mathrm{c}}$ & & & & 8.5 & 8.5 & 8.5 \\
\hline Average year & 50,833 & 44,957 & 117,950 & $19,211^{\mathrm{d}}$ & $18,980^{\mathrm{d}}$ & 17,110 \\
\hline \multicolumn{7}{|c|}{ Cost differentials relative to no dementiab } \\
\hline Total & & & & $17,861^{\mathrm{d}}$ & $15,896^{\mathrm{d}}$ & \\
\hline Average year & & & & $2,101^{d}$ & $1,870 \mathrm{~d}$ & \\
\hline$\%$ & & & & $11 \% \mathrm{~d}$ & $10 \% \mathrm{~d}$ & \\
\hline
\end{tabular}

Source: Authors' analysis of the 2006-2015 Medicare 5 Percent Limited Data Set claims files. ${ }^{27}$

${ }^{a}$ Costs were age normalized and risk adjusted to the Alzheimer decedent population.

${ }^{b} P<0.01$, using Student's t-test on average costs per beneficiary for Alzheimer disease or dementia versus no dementia.

'A beneficiary is alive, on average, half a year in the year of death. Therefore, the costs span 8.5 years.

$d P<0.01$, using repeated measures ANOVA test on average costs per beneficiary for Alzheimer disease or dementia versus no dementia.

ANOVA = analysis of variance.

On an age- and risk-adjusted basis, decedents with Alzheimer disease had costs (2015 U.S. dollars) about $\$ 18,000$ $(10.9 \%)$ higher $(P<0.01)$ on average than decedents with no dementia over the 8 years before the year of death plus the (partial) year of death, and decedents with general dementia had costs that were about $\$ 16,000(9.9 \%)$ higher $(P<0.01)$ than decedents with no dementia (Table 2 and Figure 1) per annum 2 years before death, declined somewhat the year before death, and became negative the year of death.

Cost differentials for decedents with general dementia followed a similar pattern to those with Alzheimer disease. Eight years before death, decedents with general dementia had costs per annum about $\$ 1,000(P<0.01)$ higher than decedents with no dementia. The cost differential gradually increased, peaked at $\$ 3,000(P<0.01)$ the year before death and declined to about $\$ 1,000$ the year of death.

In most years, decedents with Alzheimer disease had risk scores that were only slightly above those with no dementia, except for the year of death when the Alzheimer cohort had a risk score that was 11 percentage points lower $(P<0.01)$. Decedents with general dementia had risk scores that were 7-17 points higher than those with no dementia $(P<0.01$; Table 3$)$.

On an age-adjusted basis, at 8 years before death, the decedents with Alzheimer disease and general dementia were about $60 \%$ more likely to be dual eligible for Medicare and
Medicaid versus decedents with no dementia (about 15\% vs. $9 \%, P<0.01$ ). In later years, decedents with Alzheimer disease or general dementia were much more likely to become dual eligible. At the time of death, nearly $30 \%(P<0.01)$ of decedents with Alzheimer disease were dual eligible, about double the $15 \%(P<0.01)$ of decedents with no dementia (Figure 2$)$.

The higher cost of dementia decedents was not consistent across services. Decedents with dementia had higher costs for Medicare skilled nursing, home health services, and hospice services and had lower costs for intensive medical treatments, such as Medicare Part B drugs, in the years before death $(P<0.01)$. Medicare Part B covers many oncology and biologic drugs (Appendix B, available in online article).

\section{Discussion}

This study followed Alzheimer disease and general dementia patients covered by Medicare for up to 10 years and compared their risk-adjusted allowed costs with those of other Medicare beneficiaries. We showed that a diagnosis of Alzheimer disease adds about $11 \%$ per patient per year to Medicare costs for the last years of life. The HRS study estimated that dementia cost Medicare $\$ 2,752$ (2010 U.S. dollars) per year per beneficiary with dementia-related impairments. ${ }^{13}$ This value is similar to our average annual figures of $\$ 2,101$ (2015 U.S. dollars) for Alzheimer disease and $\$ 1,870$ for general dementia. 
The Real-World Medicare Costs of Alzheimer Disease: Considerations for Policy and Care

\section{FIGURE 1 Medicare Yearly Cost Differentials Relative to No Dementia Beneficiaries ${ }^{\text {a }}$}

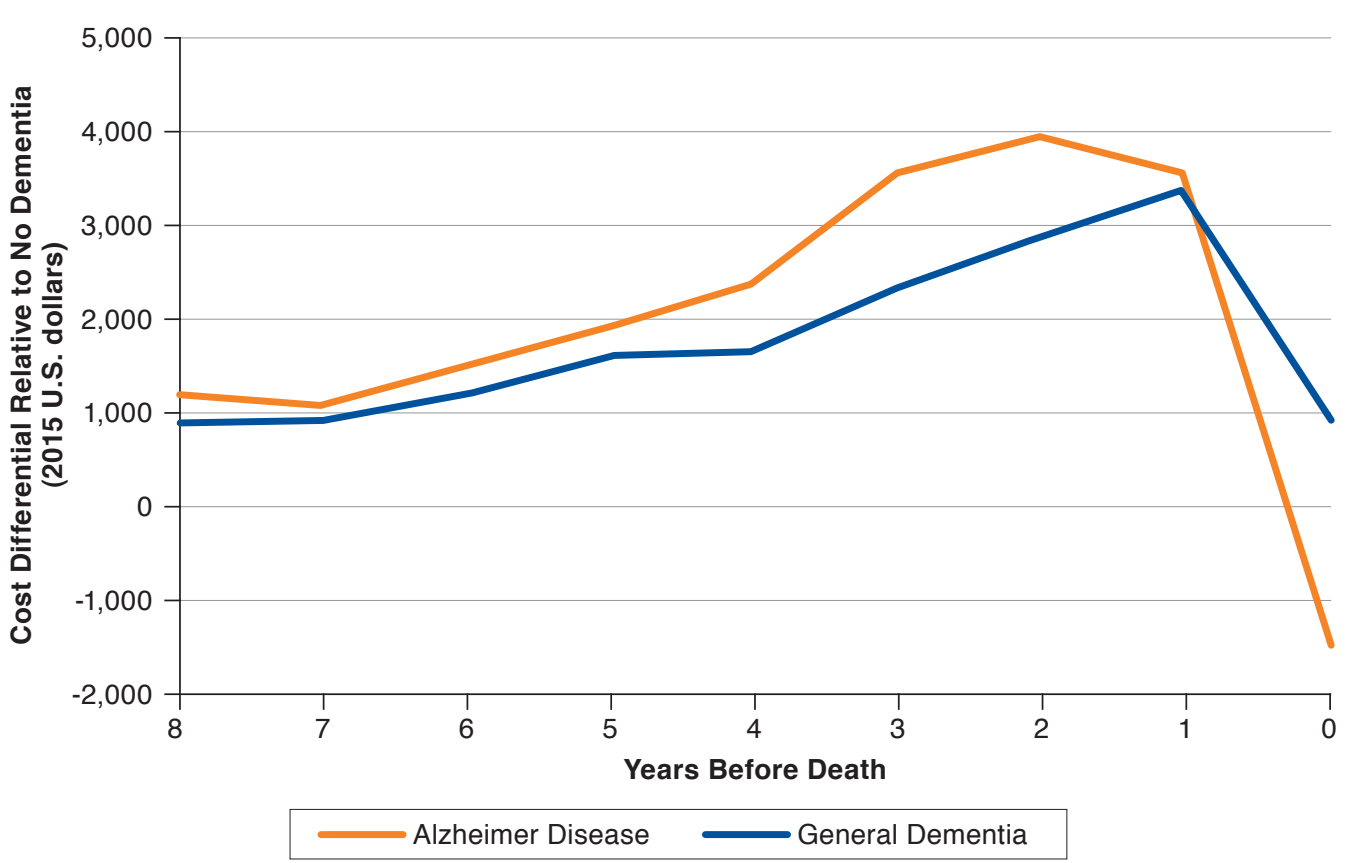

Source: Authors' analysis of the 2006-2015 Medicare 5 Percent Limited Data Set claims files. ${ }^{27}$

a $\mathrm{P}<0.01$ for the cost difference in each year shown, except Year 0 for general dementia and Year 1 for Alzheimer disease

Other publications have reported much higher Medicare costs for Alzheimer disease, ${ }^{6,13,32}$ We believe that our method of age- and risk-adjusted incremental cost methodology overcomes the biases that led to these other, higher estimates. We note that some of the high estimates report the total costs of a patient with Alzheimer disease rather than the costs that can be attributed to Alzheimer disease in general. However, it has been noted that undiagnosed Alzheimer disease increases the risk of falls and complicates the management of comorbid conditions for patients. .33,34 $^{3}$

Cross-sectional and short-term analyses of Medicare data have tended to produce higher cost estimates for Alzheimer disease than have longitudinal studies. For example, Salber et al. (2018) reported that Medicare beneficiaries with Alzheimer disease or other dementia diagnoses during a year had more comorbid conditions and more than double the costs of a matched population. ${ }^{35}$

Cross-sectional studies may incorrectly imply that the higher costs associated with a dementia diagnosis on a health insurance claim was caused by the dementia. For example, hospital care providers may be more likely to observe dementia or place a dementia diagnosis on a health insurance claim than community care physicians. Hospitals settings tend to capture more complete diagnosis codes than other settings. Furthermore, hospitalization may exacerbate the beneficiary's dementia, and the hospital caregivers may spend more time observing the patient than community care providers. Consequently, the reporting of dementia diagnosis could be an incidental finding that does not cause either comorbidities or additional cost. We found that only $11 \%$ of inpatient admissions at the time of incident Alzheimer disease diagnosis appear to be directly related to Alzheimer disease or associated care, so it is questionable whether to attribute the associated costs to Alzheimer disease. Our analysis suggests that an inpatient admission often results in the initial Alzheimer diagnosis.

Our methodology established cohorts of decedents by proximity to death, adjusted for age and comorbidities, and assigned dementia status using at least 3 years of claims before death. We chose this identification method after observing inconsistent year-to-year coding for Alzheimer disease in the claims data. For example, we found that only about one half of beneficiaries who had what appeared to be their first (incident) Alzheimer diagnosis code had an Alzheimer code the year following this incident year, and nearly one quarter had no dementia code at all in the following year.

\section{Patients with Alzheimer Disease Do Not Just Have Alzheimer Disease}

Beneficiaries with and without Alzheimer disease of the same age and proximity to death are both costly for Medicare because they are elderly, near the end of their lives, and often 
The Real-World Medicare Costs of Alzheimer Disease: Considerations for Policy and Care

TABLE 3 Risk Adjustment Differentials Compared with No Dementia Patients by Year Before Deatha,b

Risk Adjustment Differentials Compared with No Dementia by Year Before Death

\begin{tabular}{|c|c|c|c|c|c|c|c|c|c|}
\hline \multirow[b]{2}{*}{ Dementia Classification } & \\
\hline & 8 & 7 & 6 & 5 & 4 & 3 & 2 & 1 & 0 \\
\hline \multicolumn{10}{|l|}{ Risk adjustment factor } \\
\hline Alzheimer disease & $1.11^{\mathrm{b}}$ & $1.19^{c}$ & $1.26^{\mathrm{b}}$ & $1.35^{\mathrm{b}}$ & $1.45^{\mathrm{b}}$ & $1.58^{\mathrm{b}}$ & 1.72 & $1.91^{\mathrm{b}}$ & $2.15^{\mathrm{b}}$ \\
\hline General dementia & $1.20^{\mathrm{b}}$ & $1.29 \mathrm{~b}$ & $1.37 \mathrm{~b}$ & $1.47^{\mathrm{b}}$ & $1.58^{\mathrm{b}}$ & $1.70^{\mathrm{b}}$ & $1.86^{\mathrm{b}}$ & $2.08^{\mathrm{b}}$ & $2.42^{b}$ \\
\hline No dementia & 1.13 & 1.20 & 1.28 & 1.37 & 1.47 & 1.59 & 1.73 & 1.93 & 2.26 \\
\hline
\end{tabular}

Risk adjustment differential compared with no dementia

\begin{tabular}{|l|c|c|c|c|c|c|c|c|c|c|c|}
\hline Alzheimer disease & $(0.03)^{\mathrm{b}}$ & $(0.01)^{\mathrm{b}}$ & $(0.01)^{\mathrm{b}}$ & $(0.02)^{\mathrm{b}}$ & $(0.02)^{\mathrm{b}}$ & $(0.02)^{\mathrm{b}}$ & $(0)$ & $(0.02)^{\mathrm{b}}$ & $(0.11)^{\mathrm{b}}$ \\
\hline General dementia & $0.07^{\mathrm{b}}$ & $0.09^{\mathrm{b}}$ & $0.09^{\mathrm{b}}$ & $0.09^{\mathrm{b}}$ & $0.11^{\mathrm{b}}$ & $0.11 \mathrm{~b}$ & $0.13^{\mathrm{b}}$ & $0.16^{\mathrm{b}}$ & $0.17^{\mathrm{b}}$ \\
\hline
\end{tabular}

Source: Authors' analysis of the 2006-2015 Medicare 5 Percent Limited Data Set claims files. ${ }^{27}$

aDifferential calculated as Alzheimer disease/general dementia risk score minus no dementia risk score. For example, the Alzheimer average risk score in Year 0 (=2.15) is

0.11 less than the no dementia risk score in Year $0(=2.26)$

${ }^{b} P<0.01$.

${ }^{c} P<0.1$.

have multiple comorbidities and acute health events. Proximity to death is particularly important to total costs: we found that annual Medicare costs for decedents with Alzheimer disease were about $\$ 10,000$ in the eighth year before death and $\$ 32,000$ for the last half year of life (Table 2). Over their final 8 years of life, decedents with Alzheimer disease have costs about $11 \%$ higher than decedents with no dementia.

The modest Medicare cost differential between Alzheimer and non-Alzheimer decedents makes sense because there is no disease-modifying medical treatment for Alzheimer disease currently, so the extra medical costs for Medicare are low. Families or Medicaid are responsible for the majority of supportive care. We found that the added Medicare costs for decedents with Alzheimer disease are generally related to increased use of short-term supportive care, such as skilled nursing facility and home health programs (Appendix B). While it makes sense that patients with Alzheimer disease would require additional complex care, even for routine medical procedures, we also suspect that some families choose to avoid complex care, such as chemotherapy for cancer, in beneficiaries with advanced dementia. ${ }^{36}$ Such care avoidance may explain our findings of lower Part B drug costs and lower total costs in the year of death for patients with Alzheimer disease.

\section{Alzheimer Disease and General Dementia}

The data suggest possible underdiagnosis of Alzheimer disease when measured by the ICD-9/10-CM diagnosis codes that providers use when billing Medicare. We found that 18\% of Medicare decedents had 1 or more dementia diagnoses in the last 3 years of life but had no diagnoses indicating the specific cause or pathology of the dementia. We classified these decedents as having "general dementia." As shown in Figure 1, decedents with general dementia have annual costs that are within $\$ 1,000$ of Alzheimer decedents for most years, and their year-by-year patterns appear similar. This suggests potential nondifferentiation among the diagnoses.

Efforts are underway to improve Alzheimer diagnosis. The Imaging Dementia-Evidence for Amyloid Scanning (IDEAS) study, launched in 2016, is performing PET imaging on more than 18,000 Medicare beneficiaries with mild cognitive impairment or dementia to determine if their brains contain the amyloid plaques that are associated with Alzheimer disease. Although a positive test for amyloid plaques does not mean someone has Alzheimer disease, a negative result rules the disease out, ${ }^{37}$ and that patient can avoid treatments specific to an Alzheimer diagnosis. The IDEAS study was completed in December 2017, and interim results show that, of the 4,000 people initially tested, $54.3 \%$ of mild cognitive impairment patients and $70.5 \%$ of dementia patients had amyloid plaques. ${ }^{38}$ It is not clear the extent to which a diagnosis of mild cognitive impairment is a precursor to a subsequent Alzheimer diagnosis.

Some patients who received only the general dementia diagnosis codes may not receive the best care, as nonAlzheimer cognitive impairments are sometimes treatable. For any dementia patients, earlier diagnosis may give affected individuals and their caregivers better opportunity to plan care, seek available symptomatic treatment and community resources, join clinical trials, and access disease-modifying therapies when they become available. ${ }^{39,40}$

\section{Age at Death}

Decedents with Alzheimer disease are almost 5 years older than decedents with no dementia. Although Alzheimer disease can directly cause death, the 5-year age differential suggests that, for many beneficiaries, Alzheimer disease emerges alongside other diseases that cause death. Studies of death certificates support the view that Alzheimer disease may not be the cause of death for many patients with Alzheimer disease. Alzheimer disease was listed as a primary or 


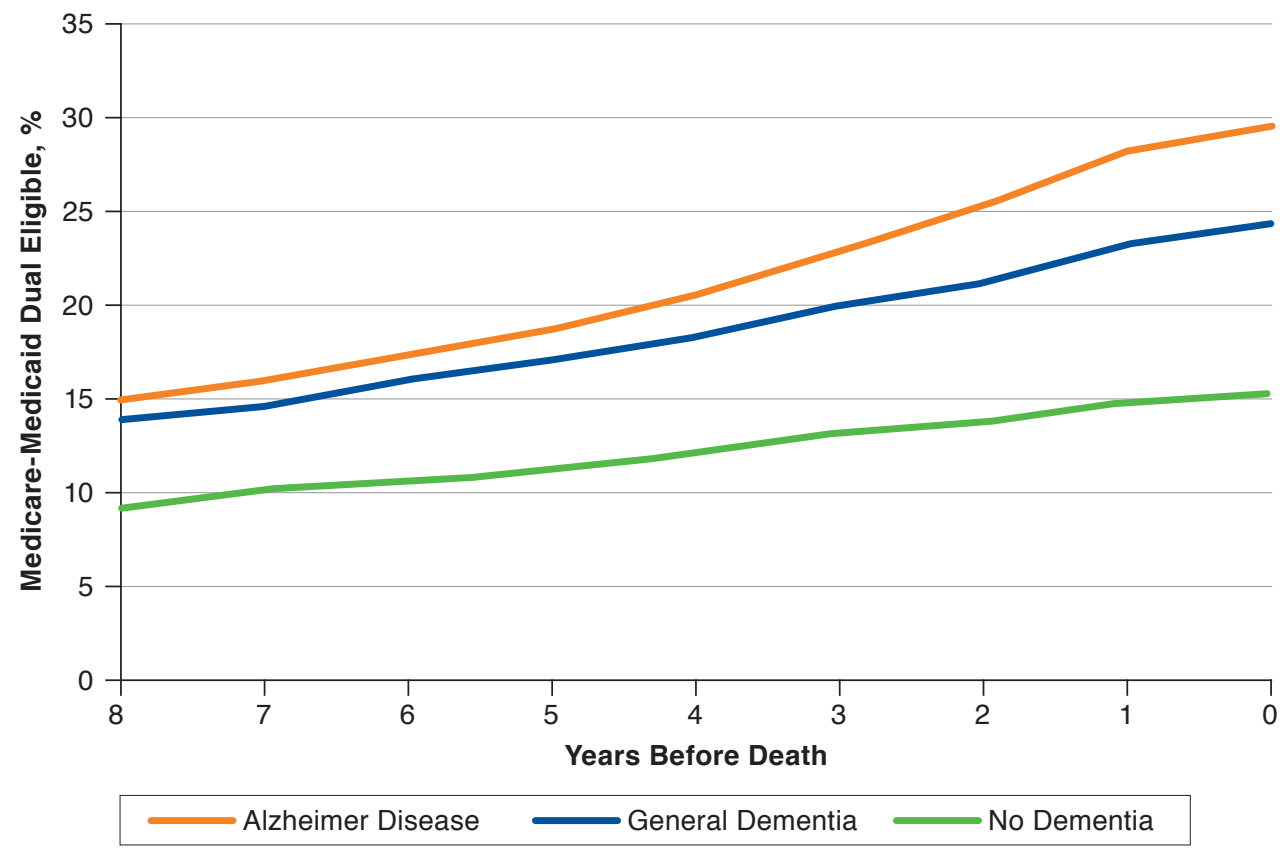

Source: Authors' analysis of the 2006-2015 Medicare 5 Percent Limited Data Set claims files. ${ }^{27}$

${ }^{a} \mathrm{P}<0.01$ for the difference in percentages for each year shown.

secondary cause on death certificates for fewer than $3 \%$ of 2009-2015 decedents aged 69 years and older, even though we found that $21 \%$ of the decedents had an Alzheimer diagnosis and another $18 \%$ had a general dementia diagnosis in their Medicare claims history. ${ }^{41}$ Underreporting of Alzheimer disease as a cause of death on death certificates has been recognized. ${ }^{42}$

\section{Policy Implications}

Medicare pays for care that is "reasonable and necessary for the diagnosis or treatment of illness or injury." ${ }^{243}$ Medicare, by statute, would cover therapies for symptomatic individuals that prevent or delay Alzheimer disease and dementia. However, Medicaid, as the primary payer of long-term services and support, such as custodial care in nursing homes and home care programs, is the government program that would benefit the most from disease-modifying therapies. ${ }^{44}$ As therapies for dementia emerge, we expect increasing debate over the balance of cost burden across payers and other stakeholders, a debate that will center around CMS.

Poverty may be responsible for some of our observed cost differential. Poverty is associated with higher medical costs, and dementia can cause income and asset loss that leads to poverty. ${ }^{44}$ We observed a higher portion of dual eligible individuals (who must be poor) among Alzheimer disease and other dementia patients. Decedents with dementia were more likely than decedents with no dementia to be dual eligible 8 years before death, when dementia impairments are likely minimal. The higher rate of dual eligibility in these early years seems more connected to long-term financial insecurity than the need for dementia-related supportive services. Decedents with dementia were also more likely than decedents with no dementia to become dual eligible in the years before death, which could be the result of beneficiary spend-down of patient financial resources because of the need for supportive services.

The adverse consequences of poor integration of Medicare and Medicaid have been a long-standing concern. ${ }^{45}$ For example, while home safety improvements can reduce hospitalizations, the extra outlay must come from out-of-pocket spending by patients or their families/caregivers or Medicaid, but the reduced hospitalizations save Medicare money. With future treatments, preventing or delaying Alzheimer disease could cost Medicare money, but the savings will largely accrue to Medicaid and families. We suggest that a way to help fund future Alzheimer therapies is through more efficiently integrating Medicare and Medicaid services and by encouraging home and community-based services, which cost less than nursing home care. Programs that offer support services for caregivers of Alzheimer disease and dementia patients have been shown 
to achieve cost savings and positive outcomes for patients and their caregivers. ${ }^{46}$

The intermittent coding of Alzheimer disease and other dementia diagnoses suggests that patients with dementia may be receiving care for other acute and chronic conditions without consistent recognition of their dementia. It seems likely that better care would result from earlier, more precise, and more consistent recognition of dementia, especially if care plans explicitly addressed self-care limitations and the need to involve family and other caregivers. Including dementia diagnoses in risk adjustment or quality-of-care measures, such as those embedded in the Medicare Star Rating System, would promote coding and could help improve care.

\section{Limitations}

We acknowledge several limitations of our study. Claims-based studies are subject to the underlying variability of clinical diagnosis and claims coding practices. The diagnoses on claims may not fully or accurately capture all the diagnoses within a patient's clinical record. Because there is no definitive diagnostic test for Alzheimer disease, some beneficiaries diagnosed with Alzheimer disease do not have the disease. Some beneficiaries with Alzheimer disease or dementia are likely undiagnosed, particularly for beneficiaries with mild impairments. ${ }^{47}$ Our methodology partially mitigates underdiagnosis by classifying decedents based on diagnoses in the last 3 years of life rather than earlier years when impairments were likely milder.

Our analysis was limited to Medicare fee-for-service beneficiaries. In 2018, Medicare Advantage enrolled approximately 33\% of Medicare beneficiaries, and the dynamics for Medicare Advantage could be different. We did not include Medicare Part D spending. The absence of dementia diagnoses from the Part D HCC risk adjuster suggests that dementia is not associated with higher or lower Part D spending. It is possible that our national average relationships do not apply uniformly by region. Our differential cost methodology used equal proximity to death to establish comparable costs. It is possible that the presence of Alzheimer disease or dementia hastens or delays death. However, this concern is lessened by our measuring time to death for any cause, rather than time to death attributed to dementia.

\section{Conclusions}

We find that the extra Medicare-covered cost associated with Alzheimer disease is modest. We believe this is because, more than for many other conditions, Alzheimer primary financial costs for supportive care are mostly paid by families and Medicaid, rather than Medicare. While our findings are consistent with those of other researchers, some advocates state much higher Medicare spending, which we believe clouds the real-world dementia-related cost burden for families and Medicaid. As research continues into Alzheimer treatments, it is not too early to consider how to better integrate Medicare and Medicaid to fund and improve patient outcomes, which will likely involve better diagnosis, treatment, and care coordination along with improved access to home and community-based services.

\section{Authors}

BRUCE PYENSON, FSA, MAAA; CHARLES STEFFENS, ASA, MAAA; TIA GOSS SAWHNEY, DrPH, FSA, MAAA; and DAVID ROTTER, PhD, Milliman, New York, New York. SUSAN PESCHIN, MHS; JAMES SCOTT, JD; and ELLEN JENKINS, BS, Alliance for Aging Research, Washington, DC.

AUTHOR CORRESPONDENCE: Bruce Pyenson, FSA, MAAA, Principle and Consulting Actuary, Milliman, 1 Penn Plaza, 38th Fl., New York, NY 100119. Tel.: 646.473.3201;

E-mail:Bruce.Pyenson@milliman.com.

\section{DISCLOSURES}

Funding for this project was provided by the Alliance for Aging Research which received funding from Biogen, Eli Lilly, and Janssen Pharmaceuticals. Peschin and Jenkins are employed by the Alliance for Aging Research. Scott was employed by the Alliance for Aging Research at the time of this study and also reports consulting fees from Piramal Imaging, General Electric, and Allergan, outside of this study. Scott is chair of the Board of Directors for the Alliance for Aging Research, which is a volunteer position, and is also president of Applied Policy, a health policy and reimbursement consultancy. Pyenson and Steffens are employed by Milliman, which was contracted to work on this study. Goss Sawhney and Rotter were employed by Milliman at the time this work was performed. Milliman is a consultant to thousands of organizations in the health care industry.

\section{REFERENCES}

1. National Institute on Aging. What Is Alzheimer's disease? Content reviewed May 16, 2017. Available at: https://www.nia.nih.gov/health/whatalzheimers-disease. Accessed May 6, 2019.

2. Bor JS. The search for effective Alzheimer's therapies: a work in progress Health Aff (Millwood). 2014;33(4):527-33.

3. Office of Disability, Aging and Long-Term Care Policy. Measuring the activities of daily living: comparisons across national surveys. 1990 Available at: https://aspe.hhs.gov/system/files/pdf/74346/meacmpes.pdf. Accessed May 6, 2019.

4. Epstein-Lubow G. A family disease: witnessing firsthand the toll that dementia takes on caregivers. Health Aff (Millwood). 2014;33(4):708-11.

5. National Institute on Aging. Alzheimer's disease fact sheet. Content reviewed August 17, 2016. Available at: https://www.nia.nih.gov/health/ alzheimers-disease-fact-sheet. Accessed May 6, 2019.

6. Alzheimer's Association. 2019 Alzheimer's disease facts and figures. Available at: https://www.alz.org/media/Documents/alzheimers-facts-andfigures-2019-r.pdf. Accessed May 6, 2019

7. National Institute for Aging. Diagnosing dementia. Content reviewed December 31, 2017. Available at: https://www.nia.nih.gov/health/diagnosingdementia. Accessed May 6, 2019. 
8. Sanchez H. Autopsy rate and physician attitudes toward autopsy. Updated April 28, 2017. Available at: https://emedicine.medscape.com/ article/1705948-overview. Accessed May 6, 2019.

9. Corrada MM, Brookmeyer R, Paganini-Hill A, Berlau D, Kawas CH. Dementia incidence continues to increase with age in the oldest old: the 90+ study. Ann Neurol. 2010;67(1):114-21.

10. Prince M, Bryce R, Albanese E, Wimo A, Ribeiro W, Ferri CP. The global prevalence of dementia: a systematic review and metaanalysis. Alzheimers Dement. 2013;9(1):63-75.e2.

11. Smith JC, Medalia C; United States Census Bureau. Health insurance coverage in the United States: 2015. P60-253. September 2015. Available at: https://www.census.gov/content/dam/Census/library/publications/2015/ demo/p60-253.pdf. Accessed May 6, 2019

12. U.S. Census Bureau. Projected age groups and sex composition of the population: projections for the United States: 2017-2060. Revised release date September 2018. Available at: https://www.census.gov/data/tables/2017/demo/ popproj/2017-summary-tables.html. Accessed May 6, 2019.

13. Hurd MD, Martorell P, Delavande A, Mullen KJ, Langa KM. Monetary costs of dementia in the United States. N Engl J Med. 2013;368(14):1326-34.

14. Kelley S, McGarry K, Gorges R, Skinner S. The burden of health care costs for patients with dementia in the last 5 years of life. Ann Intern Med. 2015;163(10):729-36

15. Public Broadcasting System. The public health crisis of Alzheimer's [videotape]. Thirteen/WNET, New York, NY. January 25, 2017. Available at: https://www.pbs.org/video/alzheimers-every-minute-counts-public-healthcrisis-alzheimers/. Accessed May 7, 2019

16. Carleton L. Could Alzheimer's really bankrupt Medicare and Medicaid? Fox News. March 1, 2017. Available at: https://www.foxnews.com/health/ could-alzheimers-really-bankrupt-medicare-and-medicaid. Accessed May 6, 2019.

17. LaMotte S. Alzheimer's: the disease that could bankrupt Medicare. CNN March 17, 2017. Available at: https://www.cnn.com/2017/03/07/health/ alzheimers-report-2017/index.html. Accessed May 7, 2019.

18. Japsen B. Alzheimer's staggering $\$ 259 \mathrm{~B}$ cost could break Medicare. Forbes. March 7, 2017. Available at: https://www.forbes.com/ sites/brucejapsen/2017/03/07/u-s-cost-of-alzheimers-eclipses250-billion/\#6lbdfla37le5. Accessed May 7, 2019

19. Caminiti S. A disease on track to bankrupt Medicare. CNBC. November 10, 2015. Available at: https://www.cnbc.com/2015/11/09/a-disease-ontrack-to-bankrupt-medicare.html. Accessed May 7, 2019.

20. Gregoire C. Rising numbers of Alzheimer's patients could bankrupt Medicare. HuffPost. March 8, 2017. Available at: https://www.huffington post.com/entry/alzheimers-medicare-costs-bankrupt_us_58beflefe 4b0d841663e25fl. Accessed May 7, 2019.

21. Sawyer N. The state of affairs in Alzheimer disease. Case Manager. 2000;11(5):61-68.

22. Riggs JA. The health and long-term care policy challenges of Alzheimer's disease. Aging Ment Health. 2001;5(Suppl 1):S138-45.

23. Centers for Medicare \& Medicaid Services. Decision memo for beta amyloid positron emission tomography in dementia and neurodegenerative disease (CAG-00431N). September 27, 2013. Available at: https://www.cms. gov/medicare-coverage-database/details/nca-decision-memo. aspx?NCAId=26 $5 \&$ NcaName=Beta+Amyloid+Positron+Emission+Tomography+in+Dementia+ and + Neurodegenerative + Disease $\& b c=A C A A A A A A Q A A A \&$. Accessed May 7 , 2019.

24. GlobalData Healthcare. Azeliragon: the third Alzheimer's failure of 2018 April 17, 2018. Available at: https://www.pharmaceutical-technology.com/ comment/azeliragon-third-alzheimers-failure-2018/. Accessed May 7, 2019

25. Medicaid.gov. Mandatory \& optional Medicaid benefits. Available at: https://www.medicaid.gov/medicaid/benefits/list-of-benefits/index.html. Accessed May 7, 2019.
26. Medicaid.gov. Home \& community based services authorities. Available at: https://www.medicaid.gov/medicaid/hcbs/authorities/index.html. Accessed May 7, 2019.

27. Centers for Medicare \& Medicaid Services. Standard analytical files (Medicare claims)-LDS. Modified August 31, 2018. Available at: https:// www.cms.gov/Research-Statistics-Data-and-Systems/Files-for-Order/ LimitedDataSets/StandardAnalyticalFiles.html. Accessed May 7, 2019.

28. Alzheimer's Association. Parkinson's disease dementia. 2019. Available at: https://www.alz.org/dementia/parkinsons-disease-symptoms.asp. Accessed May 7, 2019.

29. Centers for Medicare \& Medicaid Services. 2017 annual report of the boards of trustees of the Federal Hospital Insurance and Federal Supplementary Medical Insurance Trust Funds. July 13, 2017. Available at: https://www.cms.gov/Research-Statistics-Data-and-Systems/StatisticsTrends-and-Reports/ReportsTrustFunds/Downloads/TR2017.pdf. Accessed May 7, 2019.

30. Centers for Medicare \& Medicaid Services. Announcement of calendar year (CY) 2020 Medicare Advantage capitation rates and Medicare Advantage and Part D payment policies and final call letter. April 1, 2019. Available at: https://www.cms.gov/Medicare/Health-Plans/ MedicareAdvtgSpecRateStats/Downloads/Announcement2020.pdf. Accessed June 9, 2019.

31. Lin P-J, Maciejewski ML, Paul JE, Biddle AK. Risk adjustment for Medicare beneficiaries with Alzheimer's disease and related dementias. Am J Manag Care. 2010;16(3):191-98.

32. Lin P-J, Zhong Y, Fillit HM, Chen E, Neumann PJ. Medicare expenditures of individuals with Alzheimer's disease and related dementias or mild cognitive impairment before and after diagnosis. J Am Geriatr Soc. 2016;64(8):1549-57.

33. Albert SM, Costa R, Merchant C, Small S, Jenders RA, Stern Y. Hospitalization and Alzheimer's disease: results from a community-based study. J Gerontol A Biol Sci Med Sci. 1999;54(5):M267-71.

34. Petersen JD, Siersma VD, dePont Christensen R, Storsveen MM, Nielsen CT, Waldorff FB. The risk of fall accidents for home dwellers with dementia: a register- and population-based case-control study. Alzheimers Dement (Amst). 2018;10:421-28.

35. Salber PR, Selecky CE, Soenksen D, Wilson T. Impact of dementia on costs of modifiable comorbid conditions. Am J Manag Care. 2018;24(11):e344-51.

36. Alzheimer's Association. End-of-life decisions: honoring the wishes of a person with Alzheimer's disease. Available at: https://www.alz.org/national/ documents/brochure_endoflifedecisions.pdf. Accessed May 6, 2019.

37. Alzheimer's Association. Information about PET amyloid imaging for IDEAS study participants. October 31, 2015. Available at: https://www. ideas-study.org/wp-content/uploads/2017/01/Amyloid-PET-imaging-Facts. pdf. Accessed May 6, 2019.

38. Bahrampour T. PET scans show many Alzheimer's patients may not actually have the disease. Washington Post. July 19, 2017. Available at: https://www.washingtonpost.com/national/health-science/brainscans-show-many-alzheimers-patients-may-not-actually-have-thedisease/2017/07/18/52013620-6bf2-11e7-9c15-177740635e83_story. html?noredirect=on\&utm_term=.58cc566d26e2. Accessed May 6, 2019.

39. Herman L, Atri A, Salloway S. Alzheimer's disease in primary care: the significance of early detection, diagnosis, and intervention. Am J Med. 2017;130(6):756.

40. Dubois B, Padovani A, Scheltens P, Rossi A, Agnello GD. Timely diagnosis for Alzheimer's disease: a literature review on benefits and challenges. J Alzheimer's Dis. 2016;49(3):617-31.

41. Centers for Disease Control and Prevention. About underlying cause of death, 1999-2017. 2017. Available at: https://wonder.cdc.gov/ucd-icdlo.html. Accessed May 6, 2019. 
42. Romero JP, Benito-León J, Mitchell AJ, Trincado R, Bermejo-Pareja F. Under reporting of dementia deaths on death certificates using data from a population-based study (NEDICES). J Alzheimer's Dis. 2014;39(4):741-48.

43. Social Security Administration. Compilation of the Social Security laws-exclusions from coverage and Medicare as secondary payer. Sec. 1862. 42 USC \& 1395y. December 10, 2016. Available at: https://www.ssa. gov/OP_Home/ssact/title18/1862.htm. Accessed May 6, 2019

44. Hogan C, Lunney J, Gabel J, Lynn J. Medicare beneficiaries' costs of care in the last year of life. Health Aff (Millwood). 2001;20(4):188-95.

45. Medicare Payment Advisory Committee. Issues affecting dual-eligible beneficiaries: CMS's financial alignment demonstration and the Medicare Savings Programs. June 2016. Available at: http://www.medpac.gov/docs/ default-source/reports/chapter-9-issues-affecting-dual-eligible-beneficiariescms-s-financial-alignment-demonstration-and-t.pdf?sfvrsn=0. Accessed May 6, 2019.
46. Long KH, Moriarty JP, Mittelman MS, Foldes SS. Estimating the potential cost savings from the New York University Caregiver Intervention in Minnesota. Health Aff (Millwood). 2014;33(4):596-604.

47. Bradford A, Kunik ME, Schulz P, Williams SP, Singh H. Missed and delayed diagnosis of dementia in primary care: prevalence and contributing factors. Alzheimer Dis Assoc Disord. 2009;23(4):306-34. 
The Real-World Medicare Costs of Alzheimer Disease: Considerations for Policy and Care

APPENDIX A Methodology

0. Data

We used the Medicare 5\% sample data for years 2006 to 2015. Unique identifiers allow beneficiaries to be tracked.

1. Identified decedent population

We required that decedent beneficiaries be enrolled in fee-for-service (FFS) Medicare (Part A and B) for three full calendar years prior to the year of death and the year of death. Therefore deaths for the study population occurred between 2009 and 2015.

Note: Requiring three years of enrollment takes into the intermittent nature of dementia diagnosis coding and also eliminates beneficiaries who move from Medicare Advantage plans to FFS at the end of life for hospice or skilled nursing services.

2. Assigned each decedent to a "dementia classification at death"

For each decedent beneficiary we scanned all qualified diagnosis codes for services provided during the three years prior to death and the year of death and classified the beneficiary by the highest diagnosis dementia code.

Qualified services includes claims for acute and non-acute inpatient admissions, emergency department care, observation care, and outpatient facility services and physician evaluation and management services. Qualified claims do not include laboratory, imaging, and other diagnosis services as the diagnoses codes for these services may include "rule out" diagnoses. See Qualifying Codes tab (available from the authors by request).

Dementia diagnoses and the classification hierarchy are shown in the ICD Diagnosis Codes tab (available from the authors by request).

3. Adjusted all costs to 2015 levels

We adjusted 2007-2014 costs to 2015 levels by applying Part A and B trend factors developed from the 2016 and 2017 Medicare Trustee's Reports. See the Trend Adjustment tab (available from the authors by request).

4. Calculated risk adjustment factors

We calculated a risk score for each beneficiary and each calendar year, using the beneficiary's diagnosis codes, age, and sex for the prior calendar year. We used the 2015 CMS-HCC methodology and the 2015 non-institutional, non-dual risk factors, with OREC status=age 65, except we assigned a factor of 8.00 if the beneficiary's Medicare enrollment status was ESRD.

Note: The 2015 CMS-HCC methodology does not assign a risk score for Alzheimer's and general dementia diagnoses. We did not adjust for institutional, dual, and non-age 65 OREC status as these statuses may be the result of dementia.

\section{Adjusted risk factors to 2015 levels}

Because risk factors have increased over the years due to more careful diagnosis coding, we adjusted 2007-2014 risk scores to 2015 levels by applying trend factors developed from the average risk score of the national Medicare $5 \%$ sample. The trend factors are shown in the Risk Adjustment tab (available from the authors by request).

\section{Calculated costs - by dementia classification at death, age band at death, and years before death}

We calculated total Part $A+B$ costs for the year of death and for up to 8 years of enrollment prior to death by classification at death, age band at death, and years before death.

Note: All beneficiaries had Part $A+B$ enrollment for the year of death and the 3 years prior to death and progressively fewer had enrollment for years 4 to 8 . The costs for the year of death are, on average, for six months of enrollment. 


\section{APPENDIX A Methodology (continued)}

Note: Study population beneficiaries who died under age 69 were eligible for Medicare due to disability for some or all of the 3 years of Part $A+B$ enrollment that we require for study inclusion. Alzheimer's is also relatively uncommon for people in their 60 s. As a result, the $<69$ age band has few decedents and compared to the other age bands appears atypical. We therefore calculate costs in aggregate for decedents ages $69+$, excluding the younger decedents.

\section{Calculated risk adjusted costs}

Using the average adjusted risk factors, we adjusted the costs for general dementia and no dementia decedents to the risk levels of the Alzheimer's decedents.

\section{Calculated risk adjusted cost differentials}

Using the average adjusted risk factors, we adjusted the costs for general dementia and no dementia decedents to the risk levels of the Alzheimer's decedents and then calculated risk adjusted cost differentials.

\section{Calculated age-normalized costs for ages $69+$}

We calculated age-normalized costs, risk adjusted costs, and cost differentials for all ages 69+ by using the distribution of Alzheimer's decedents by age band across all years and dementia statuses.

Note: We risk adjust and age-normalize costs using the characteristics of the Alzheimer's decedents. This allows us to estimate what the costs for the Alzheimer's decedents would have been if they had not had Alzheimer's. 


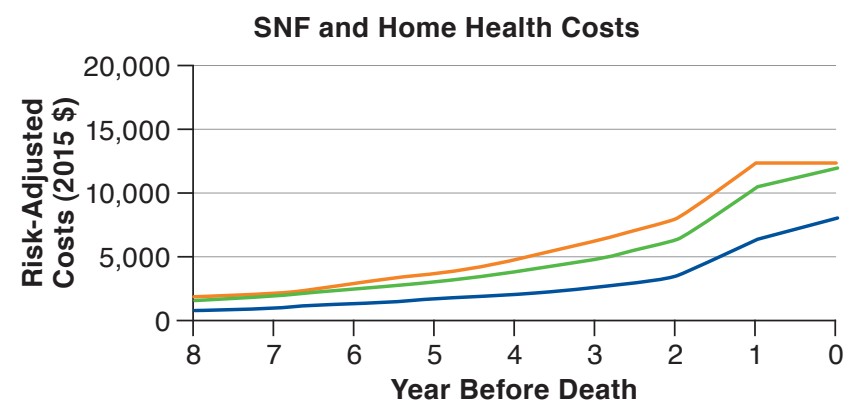

- Alzheimer — General Dementia —No Dementia

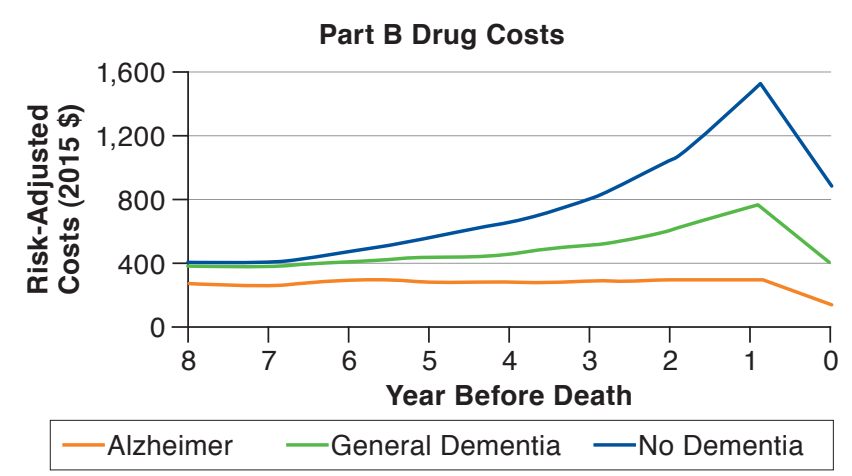

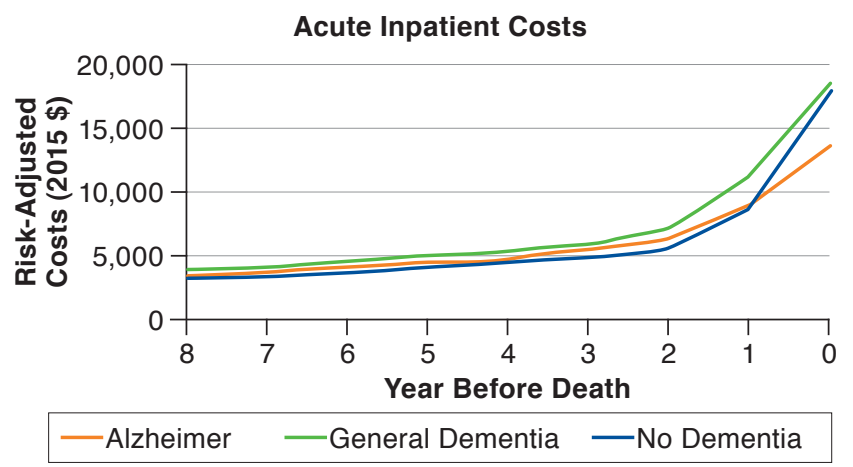

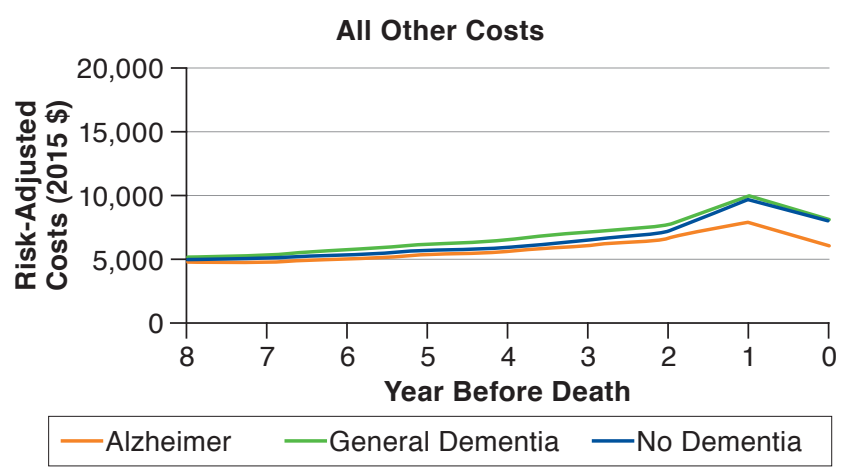

Source: Authors' analysis of the 2006-2015 Medicare 5 Percent Limited Data Set claims files. ${ }^{27}$ SNF = skilled nursing facility. 